\title{
STUDENT PROJECT Deaccessioning: A Curatorial Review
}

\section{Connor Smith ${ }^{1}$}

\begin{abstract}
Deaccessioning in collections can be controversial because of the value associated with some taxa and their conservational, historical, educational, display and research significance within the collection. Twenty-one horticultural institutions completed a survey on the protocols for deaccessioning plant material. The resulting data were collated to provide a comparison of the different approaches institutions take towards deaccessioning their collections. This study has identified that conservation and education are the most important factors in managing garden collections. Accession data of high quality is an essential part of managing a collection, but poor accession data should not be a reason to deaccession plants. Space constraints are the primary factor behind the deaccessioning of collections. This paper is a summary of the research project completed by the author for the BSc in Horticulture with Plantsmanship at the Royal Botanic Garden Edinburgh (RBGE).
\end{abstract}

\section{Introduction}

Deaccessioning is fraught with paradoxes, oxymorons, and subjectivism (Paradoxia Epidemica cited in Stam, 1982).

The removal of an item from an existing collection - deaccessioning - has historically been a controversial topic and continues to be so. Several studies have indicated that it is not often talked about (Sonderman, 1996; Greene, 2006). A survey conducted by Cook (2000, cited in Greene, 2006) of 315 pieces of literature revealed that only 11 (3.5 per cent) were specifically about reappraisal and/or deaccessioning. Greene states that there is a degree of fear associated with deaccessioning because it can often be impossible to regain an item once it has been removed. However, several studies (Greene, 2006; Society of American Archivists, 2017) agree that it is an essential process within garden collections when it comes to managing space, time and resources.

Deaccessioning is often misunderstood (Vecco \& Piazzai, 2015). The biggest misconception is that deaccessioned material is simply 'thrown away' or composted as it is no longer of importance (Blackmore, 2008). This is very rarely the case; as Blackmore explains, a more accurate description of deaccessioning is the transfer of material to other collections, considered positive and of conservation value.

As a student at the Royal Botanic Garden Edinburgh (RBGE), the author acquired a greater understanding of collection management by studying both the living collection - comprising approximately 35,500 accessions - and the herbarium, which contains approximately 3 million specimens (Rae et al., 2006). These collections provided the resources required to analyse the practice

${ }^{1}$ Connor Smith was a student on the BSc in Horticulture with Plantsmanship at the Royal Botanic Garden Edinburgh (RBGE) and completed the course in 2020.

Address: Budapestlaan 17, 3584 CD Utrecht, Netherlands.

Email: c.j.smith@uu.nl 
of deaccessioning across multiple aspects of the collection. At RBGE specimens considered for deaccessioning are evaluated on a case-by-case basis. This is time-consuming and labour-intensive but nonetheless important due to the multiple factors which must be considered each time, such as the historic value, provenance and genetic traits associated with an individual accession. Other considerations may be more subjective, for instance ornamental value, but are also important in the context of the organisation's objectives.

\section{Background information}

\author{
An accession or an acquisition is 'a new \\ item added to an existing collection' \\ (Oxford Dictionary, 2015).
}

The term 'accession' is used not only in the context of the collections in museums and galleries but also with reference to living collections of plants, such as that of RBGE. Many institutions have an accessioning (or acquisition) policy, which provides a detailed framework on how an organisation can acquire material and which material is prioritised, as well as a list of justified recommendations (Rae, 1994). Plant material that enters RBGE is collected legally and in strict accordance with the laws and agreements governing plant collection and export, such as the Convention on International Trade in Endangered Species of Wild Fauna and Flora (CITES), the Convention on Biological Diversity (CBD), the Nagoya Protocol and any additional laws regarding wild-collected material (WCM) (Thomas \& Watson, 2000).

\section{Purpose of a botanic garden}

It is important to first define what a garden requires in order to be considered a botanic garden. A botanic garden is described by Rae (1995) and Botanic Gardens Conservation International (BGCl) (2012) as a scientific and educational facility that is open to the public, keeps plant records, maintains labels and undertakes some type of research. It must additionally deliver elements of public education, engage in active in situ and ex situ conservation, and provide horticultural training.

In recent years conservation has become of greater importance to botanic gardens due to climate change, land use change and the biodiversity crisis (RBGE, 1994; BCGI, 2012). Therefore, many botanic gardens identify their purpose as being to educate visitors on plant exploration and introduction, research, and conservation of both natural habitats and ex situ collections (Frediani, 2009).

\section{Accessioning at RBGE}

On average RBGE receives over 2,000 individual accessions of plant material (seeds, propagules or potted specimens) each year (Rae et al., 2012). Of that total, an estimated 79-92 per cent is of wild origin (Rae, 2004). New material must be checked for pests and diseases, its identity verified if possible and paperwork checked for compliance with international and internal protocols. Once approved it is then given a unique accession number (Rae et al., 2006; Glasgow Botanic Gardens, 2016). The new accession requires the name of the species, authority, provenance, source, collector name and number, and type of material (whether this is living plants or auxiliary dried material for the extraction of DNA), all noted in full (Thomas \& Watson, 2000).

The quality of information is imperative for plant material of conservation importance, such as accessions belonging to the International Conifer Conservation 
Programme (ICCP) at RBGE (Threatened Conifers, 2019). The ICCP has developed over 2,000 safe sites, with 15,000 individual conifers representing 155 conifer taxa, 95 of which are threatened (Threatened Conifers, 2019). It highlighted the importance of accession information in a study conducted by Allnutt et al. (1999), whereby the genetic diversity of specimens of Fitzroya cupressoides were tested to establish the genetic value of existing ex situ collections.

The educational, conservational and research value of a collection is largely dependent on the quality of the accession data (Badley et al., 2004). Inadequate accession information can reduce the overall value of a collection and can cause problems such as increased resources and time being required to locate the missing data. The most valuable collections are those in which the plants collected are verified and accession data are frequently evaluated and updated consistently (Badley et al., 2004; Rae et al., 2006).

\section{Number of accessions per taxon at RBGE}

Reducing high numbers of accessions per taxon is a common reason for undertaking the process of deaccessioning. At RBGE, for example, the number of accessions per taxon is consistently kept low to allow the highest overall level of diversity (Rae et al., 2006). However, imposing a blanket 'maximum number of accessions' to keep this number low would be misguided. The more accessions per taxon, the more genetic variation is preserved in the collection; furthermore, this reduces the potential loss of valuable material. Exceptions are therefore made with plants of specific interest, as multiple accessions of a single taxon will give the highest genetic diversity (Blackmore,
2008). For example, species with a wide geographic distribution can show extreme variability due to phenotypic plasticity and ecotypes; it is therefore important to collect multiple individuals from a broad geographical range (Gardner \& Thomas, 1996; Christian, 2008).

This approach has been taken in the Rhododendron collection and in the conservation hedges, specifically with the following species: Taxus baccata, Prumnopitys andina and Saxegothaea conspicua (Gardner et al., 2019). A hedgerow allows the establishment of large volumes of WCM in a confined space (Christian, 2008). Having a wide range of genetic material in ex situ collections is imperative to avoid genetic bottlenecks should subsequent offspring be intended for reintroduction to the wild (Gardner \& Thomas, 1996).

\section{Deaccessioning}

\section{Living collections}

Before deaccessioning can take place, the conservation, historical, educational, display and research values of the accession need to be considered (Table 1). Reasons for deaccessioning are many, and can include:

- Replacement by more valuable plants/ wild-origin material

- Transfer to another botanic garden

- Removal due to no longer fulfilling the purpose of the collection

- Susceptibility to pest/diseases

- The accession being identified as a weed/ invasive species

Since the 1980s deaccessioning has become acknowledged as part of good collection management practice (Society of American Archivists, 2017). When an accession dies it should not be removed from the records; 
Table 1 Areas of value to consider before an accession is removed from the collection.

\begin{tabular}{|c|c|}
\hline Conservation & $\begin{array}{l}\text { How rare is the species? } \\
\text { Does the accession hold unique genetic material (this is possible if it is wild } \\
\text { collected). } \\
\text { Is it classified in one of the International Union for Conservation of Nature } \\
\text { (IUCN) endangered categories? } \\
\text { Is it culturally rare? An example of this would be a cultivar which is associated } \\
\text { with a small area, garden or country. It is imperative that the information is up } \\
\text { to date and includes subspecies or varieties if relevant. }\end{array}$ \\
\hline History & $\begin{array}{l}\text { Is the accession of great significance to the collection or of significant historic } \\
\text { value? }\end{array}$ \\
\hline $\begin{array}{l}\text { Education } \\
\text { and training }\end{array}$ & Is the accession used to demonstrate to learner groups? \\
\hline Display & $\begin{array}{l}\text { How ornamental is the accession? This is subjective, but consideration should } \\
\text { be given to year-round interest and visitor appeal. }\end{array}$ \\
\hline Research & Is the accession used for taxonomic, phenological or major flora research? \\
\hline
\end{tabular}

instead, the status should be updated so that $\mathrm{BGCl}$ can keep track of all accessions, living and dead (BGCl, 2019).

Pests and diseases can seriously affect collections which can in turn force the deaccessioning of infected plants to preserve the rest of the collection. For example, Phytophthora sp., Hymenoscyphus fraxineus and Xylella fastidiosa have made it increasingly difficult to propagate, grow and transport some taxa (NCBG, 2017).

There may also be disagreements over whether or not to deaccession certain specimens, or, indeed, whether to deaccession plants at all. The increase in maintenance and preservation costs coupled with the fact that municipal support for public and private gardens is continually being reduced and restricted means that deaccessioning is one of the most difficult decisions that must be made (Vecco \& Piazzai, 2015).

The importance of preserving the most threatened species is clear in the context of species conservation and declining biodiversity. Several studies (NCBG, 2017; Rae et al., 2006; Glasgow Botanic Gardens, 2016) agree that rare species must be prioritised.

\section{Herbaria}

Although the focus of this study is living collections, herbaria are an important resource for a botanic garden. Herbarium specimens made from living collections provide a permanent account of an accession, should the living material be lost or deaccessioned. However, just because a specimen is stored in the herbarium does not mean that it is acceptable to deaccession a living plant: some specimens in herbarium collections do not have a complete set of information recorded with them on their taxonomy, the coordinates, altitude and habitat from which they were collected, or the collector's name, for example, and therefore cannot be relied upon as a back-up to the deaccessioned living material (Colleran, 2013). Specimens should therefore be digitised before deaccessioning, and accurate data should be collected to keep a well-documented electronic account (Suzanne Cubey \& Elspeth Haston, pers. comm.). A further point with regard to herbaria is made 
by Benedict (1984), who argues that lack of use should not be a reason to deaccession material.

\section{Living collection policy}

A living collection policy (LCP) is a document containing the accessioning and deaccessioning policies. An accessioning policy is a set of guidelines according to which plants may enter a botanic garden with respect to its collection development targets. Each acquisition must therefore conform to the collection development targets detailed in the LCP (Dossman, 2016). A deaccessioning policy informs the removal of plants that no longer fit with these targets.

A garden's aims and objectives must be clear, and the LCP forms part of the strategic approach towards meeting these. As with any institutional policy, frequent evaluation of the LCP is required to ensure its ongoing relevance (France, 2019). However, during the course of the author's preliminary research, it became evident that not all gardens had an LCP and therefore did not have a written accessioning or deaccessioning policy. This informed the author's decision to carry out a survey to gain additional information on living collection policies, and accessioning and deaccessioning practices.

\section{Transfer of material}

A key form of deaccessioning is the transfer of plant material to another botanic garden. Before the material can be transferred the completion of a material transfer agreement must be agreed upon, subject to CITES, the CBD and the Nagoya Protocol. Consent from the country of origin may also be required (Thomas \& Watson, 2000). Collections such as the Zingiberaceae, Begoniaceae, Gesneriaceae, Ericaceae, ICCP and Global Conservation Consortium for Rhododendron
(GCCR) collections at RBGE are of great conservation importance. They are under threat in their native range, so it is essential that these collections be shared in order to increase opportunities for their conservation (Rae et al., 2006).

Concerns regarding the transfer of material are justified, however, and can inhibit decisions to deaccess the material to other organisations. For example, in 1993, the Zingiberaceae collection at RBGE was deaccessioned to its smallest propagule size due to a halt in taxonomic work, and a complete copy of the collection was sent to another botanic garden (Blackmore, 2008). Sadly, the recipient garden had funding issues and the entire collection died. A few years later RBGE acquired a new Zingiberaceae taxonomist and began to rebuild the collection it had lost (Blackmore, 2008). This highlights the vulnerability of collections and the importance of sharing material with care.

\section{Cultivars vs wild-collected material}

As more botanic gardens focus their aims and objectives on conservation, many gardens have chosen to deaccess cultivars in favour of WCM. While WCM is of great importance in terms of conservation and research, it is often poorly represented in botanic gardens, as shown in a survey conducted by Maunder et al. (2001) of 119 European botanic gardens. This survey found that most of the plant collections showed limited plant diversity and contained a large proportion of non-wild origin accessions.

RBGE pledged to increase WCM from 53 per cent to 60 per cent by 2024; the LCP (Rae et al., 2006) states that the garden should be 'overwhelmingly dominated by well-documented, wild origin plants'. Focus was placed on specimens originating from 
vulnerable areas in biodiversity hotspots such as China, Nepal and Chile that can survive in the Scottish climate.

The estimated current figure of cultivated taxa is 15 per cent with the recommended figure being 12 per cent. Historically it has been considered appropriate to plant cultivated material in the public areas of the Garden; in recent years, however, there has been increasing interest in utilising public areas for WCM instead (Rae et al., 2006).

Certain cultivars possess qualities of conservation, historical, educational, display and research interest and should therefore be retained despite being of garden origin. For example, Berberis $\mathrm{x}$ stenophylla is a hybrid of historical parentage: $B$. darwinii and B. empetrifolia. B. darwinii was found by Charles Darwin in 1835 during the Beagle voyage and subsequently named for him by Joseph Hooker (1844). The two species are phytogeographically and phylogenetically separated (Kim et al., 2004). Therefore, the hybrid could only be formed in an artificial environment, in this case the Fisher, Holmes \& Co. nursery in Handsworth, near Sheffield, in the 1860s. It was this nursery that introduced B. empetrifolia into the trade in 1827 (International Dendrological Society, n.d.).

\section{Objectives}

The project summarised here provided a detailed protocol on the process of deaccessioning plants. This paper identifies the main horticultural and curatorial issues relating to the project and addresses them in the form of a list of justifiable recommendations.

\section{Method}

A survey was selected as the most appropriate form of data collection. This method allowed the largest collection of data in order to gain an overview of global accessioning and deaccessioning practices. Google Docs was selected as the preferred survey format. The survey incorporated both qualitative and quantitative data to improve the opportunities for data analysis. A combination of both types of data is regarded as the best approach (Kelle, 2008).

$\mathrm{BGCl}$ has over 600 members in more than 100 countries, with a network of around 60,000 plant scientists and horticulturists ( $\mathrm{BGCl}, 2019$ ). The American Public Gardens Association (APGA) has approximately 600 members in 20 countries (APGA, 2021). BGCI and APGA provided the best platform for survey distribution. The two organisations distributed the survey to botanic gardens via email and their newsletters Cultivate (BGCI) and Public Garden (APGA). A total of 21 botanic gardens responded and completed the survey. Randall (1991) states that conducting a survey externally removes any potential bias; for this reason, RBGE was not included.

The information gathered in the initial literature review was collected and used to form the key questions which were further developed. The survey was split into three clear sections. Each section included a short introduction and background to the topic.

Section 1 introduced the dissertation topic and provided an outline of the survey. It asked the respondent to confirm that they were over 18. Other questions established the type of horticultural institution the respondent represented and its area of focus.

Section 2 sought information on the accession policies of the horticultural institution in order to form an understanding of the process of accessioning plant material, data collection and the type of plant material 
involved - wild-collected vs cultivated/garden origin.

Section 3 related to the deaccessioning policies of the respondent's institution. Questions covered the process by which plant material was deaccessioned, reasons for deaccessioning, frequency and any other important factors to be considered before plants were deaccessioned.

Responses were analysed by reviewing them both individually and collectively to identify key differences or commonalities within the data set (Flick, 2009). Notable findings were recorded to see if any overarching themes were present (Richards, 2005).

\section{Results}

The respondent demographic was as follows: 16 out of 21 (75.8 per cent) were botanic gardens, 3 out of 21 (14.3 per cent) were arboreta and 2 out of 21 (9.5 per cent) were display gardens. By agreement, the respondents have been anonymised for this report.
Fig. 1 shows the five key areas of botanic garden activity identified in the literature review rated according to level of importance by each respondent.

Education was regarded as the most important activity for most respondents. Conservation was the next most important, with 8 out of 21 considering it essential, and 18 out of 21 considering it important or essential. Fifteen respondents considered research important or essential. Less importance was placed on display and recreational green space than on the other areas.

\section{Accessioning policies}

Respondents were asked whether their garden had an accessioning policy.

Of the 21 gardens, 14 do have a written accessioning policy, 6 do not and 1 was uncertain (Fig. 2).

While 85 per cent of gardens (18 of the 21 respondents) record plant information according to the suggested standards for collection data, the data presented on plant

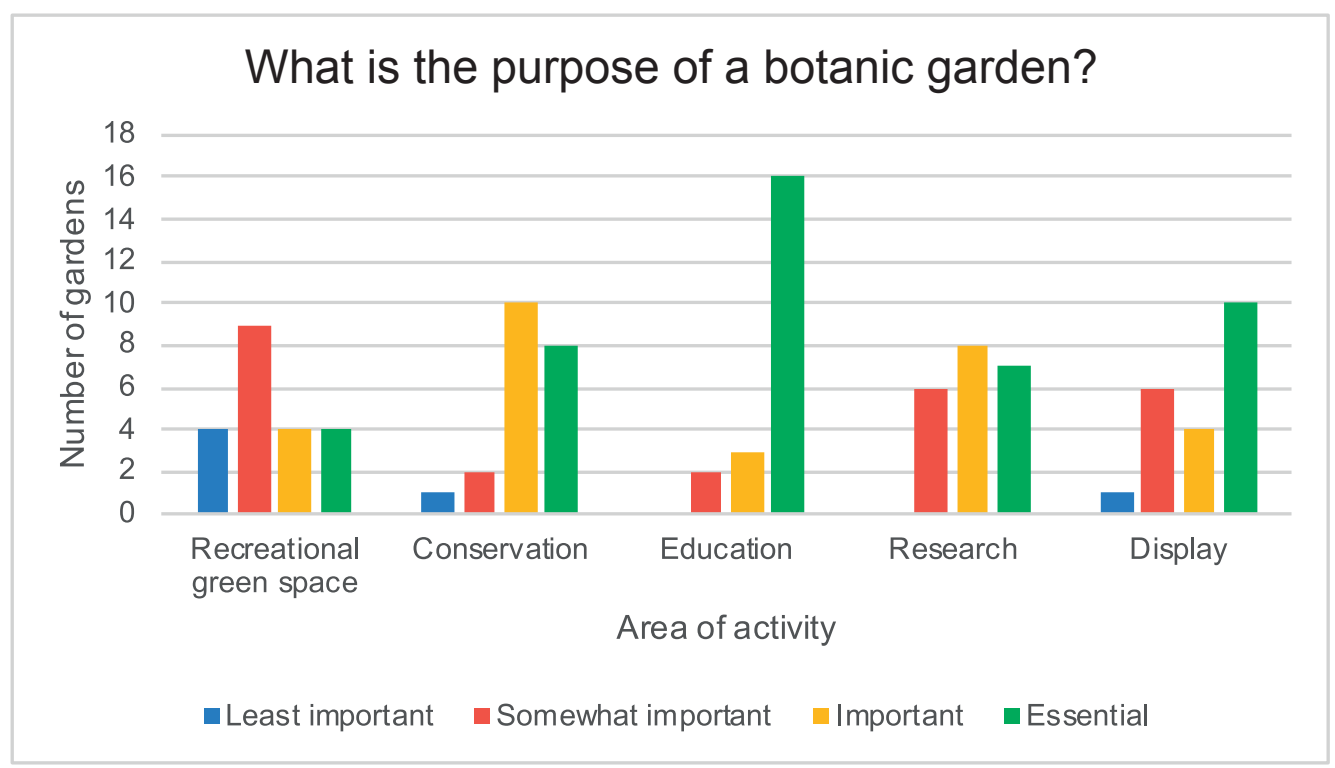

Fig. 1 Key areas of botanic garden activity rated according to their level of importance. 


\section{Does the garden have a written accession policy?}

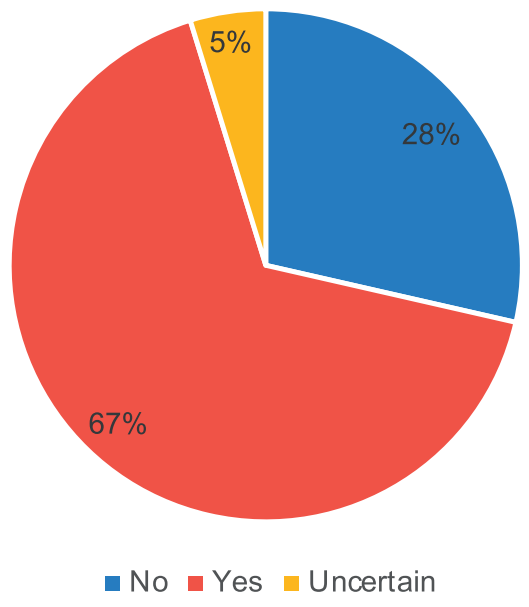

Fig. 2 Percentage of respondents whose garden has a written accessioning policy.

labels in the collections tends to be minimal, in accordance with standards suggested by Thomas \& Watson (2000) (Fig. 3).

Of the 21 respondents, 18 were willing to provide data on the ratio of wild-collected species to cultivated material for comparison
(Fig. 4). Wild-collected species represented an average of 20 per cent of the collections, while cultivated material - accessions not of known wild origin - represented 74 per cent. Five of the respondents had collections of uncertain origin.

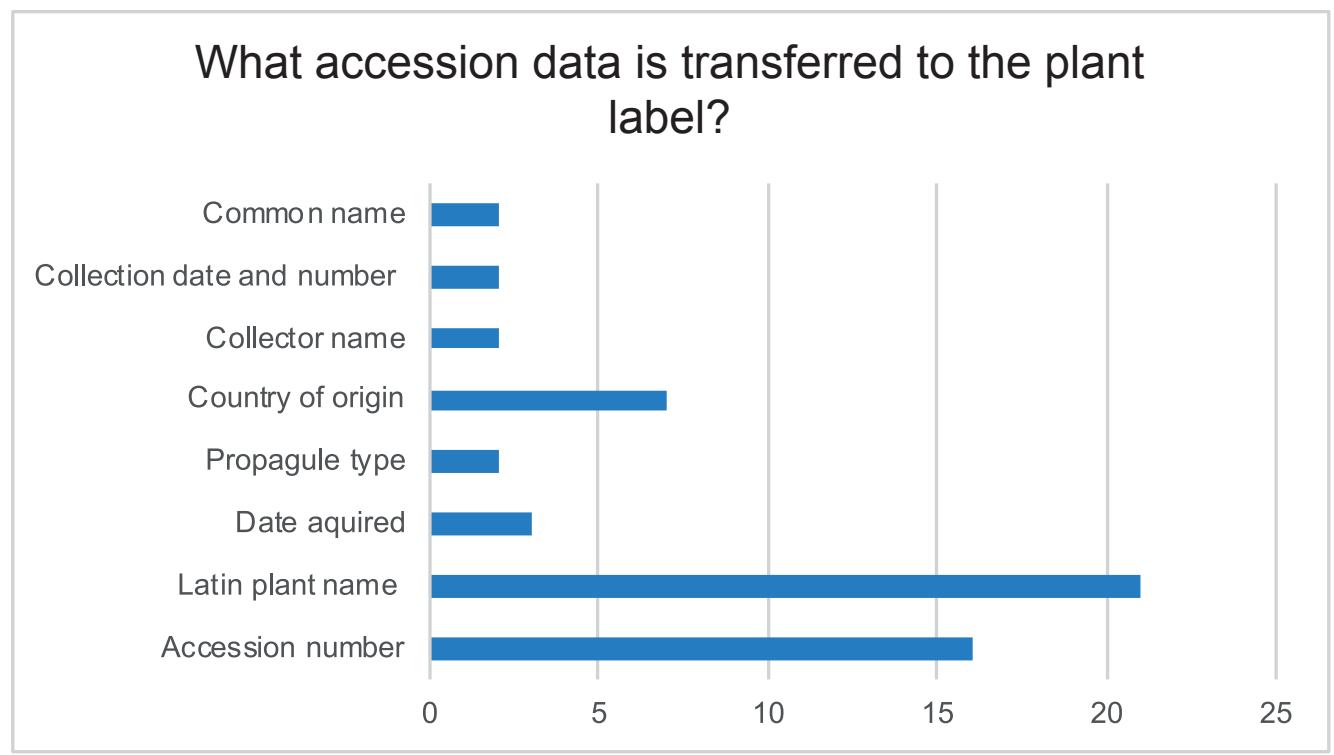

Fig. 3 Information available on plant labels. The figures on the horizontal axis indicate the number of respondents who display this information on plant labels in their respective institutions. 


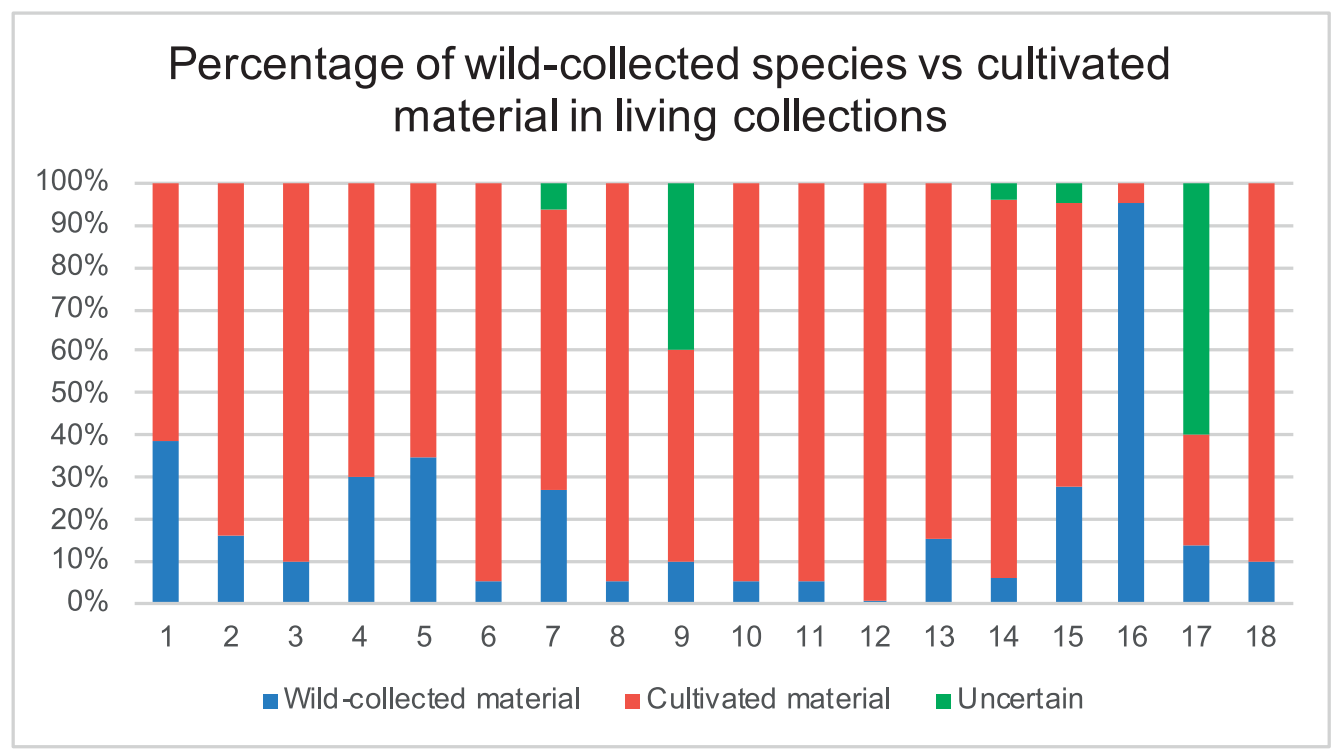

Fig. 4 Percentages of wild-collected species and cultivated material in the 18 responding institutions.

\section{Deaccessioning policies}

Of the 21 responding institutions, 13 (62 per cent) have a written deaccessioning policy (Fig. 5) and 14 (67 per cent) a written accessioning policy.
A total of 13 out of 21 respondents (61 per cent) disagreed with deaccessioning material that has poor data (Fig. 6). This raises an important question: is the material with poor associated data worth keeping because it is rare (and therefore there is limited data

\section{Does the garden have a written deaccessioning policy?}

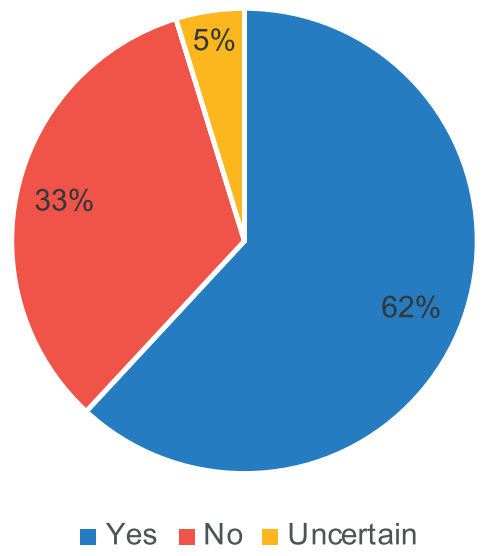

Fig. 5 Percentage of respondents whose institution has a written deaccessioning policy. 


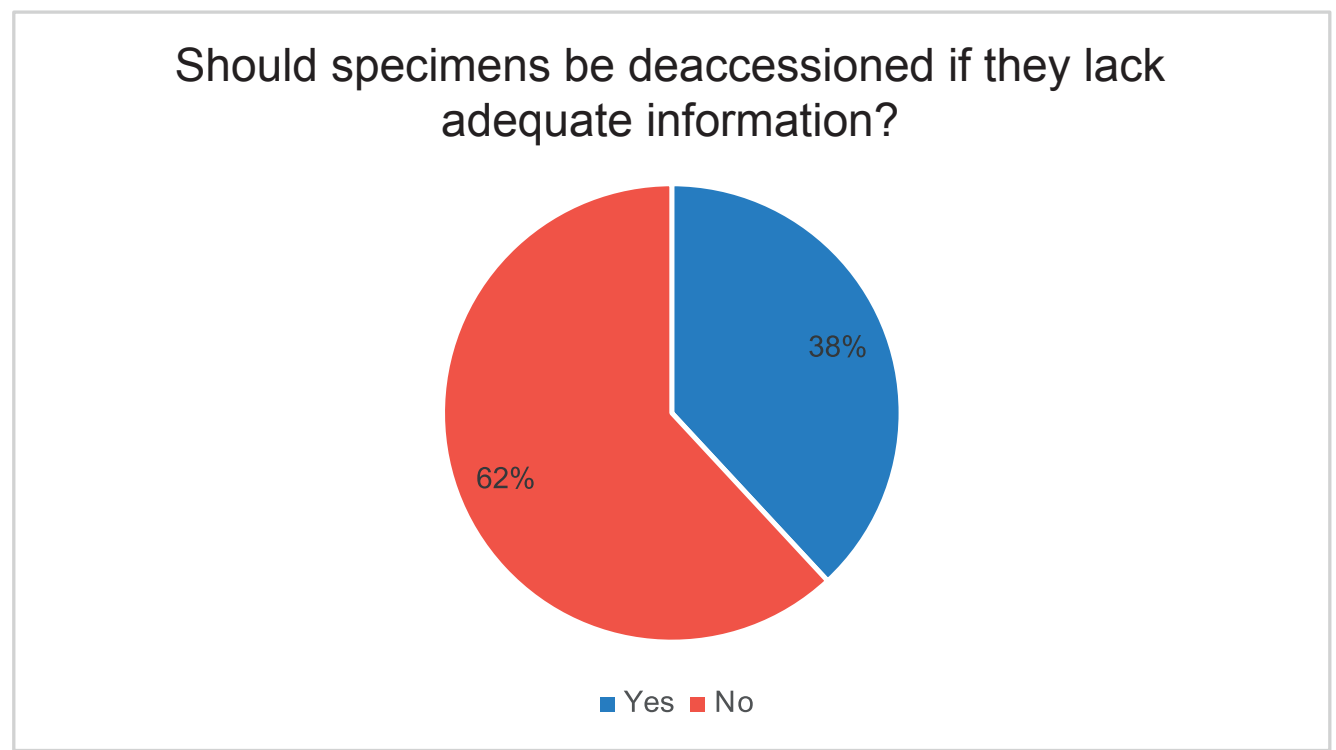

Fig. 6 Percentage of respondents who believe specimens should be deaccessioned if they do not have adequate associated information.

available) or does the accession not meet the minimum standards requirements due to poor data collection management (Thomas \& Watson, 2000)?

Five key areas to consider before deaccessioning were identified in the literature review in Table 1. The respondents were asked to rate some of these factors according to importance (Fig. 7). Conservation was by far the most important criterion with 16 out of 21 agreeing it was essential.

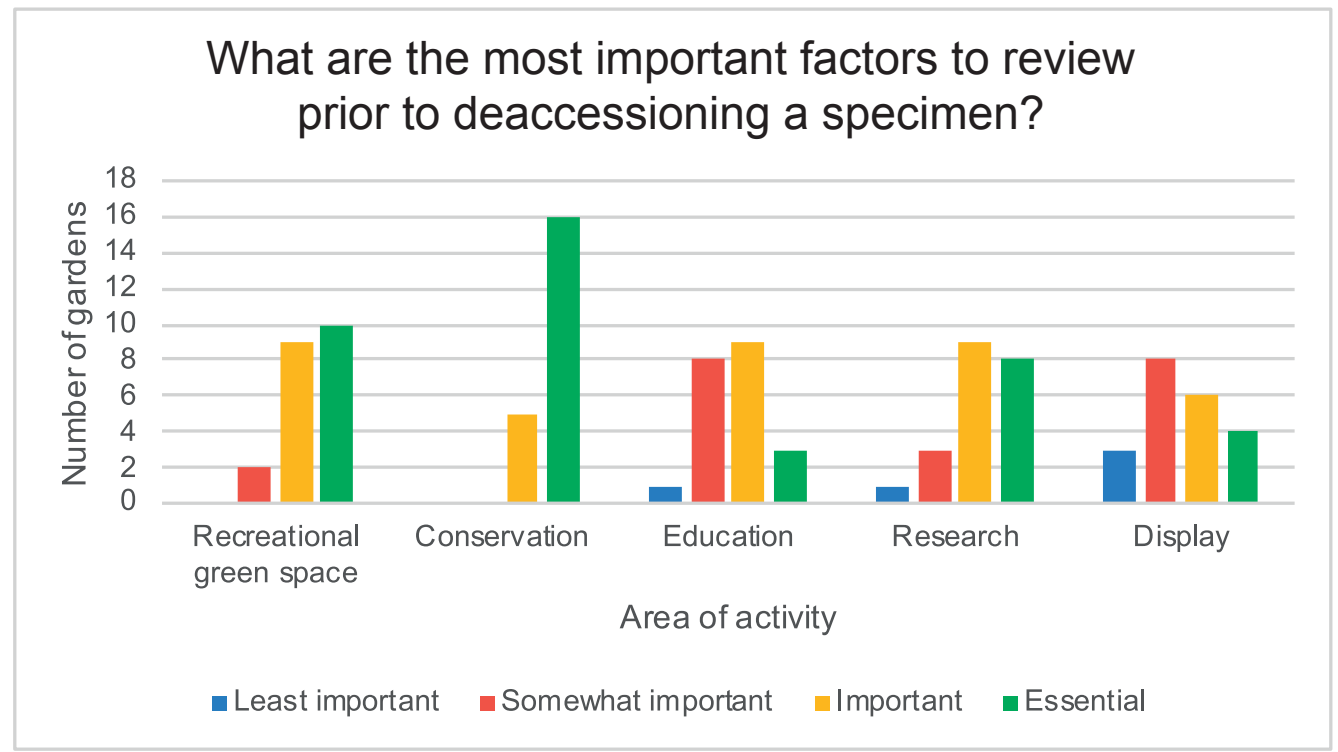

Fig. 7 Key areas of botanic garden activity to consider before deaccessioning, rated according to level of importance. 


\section{The Chinese Hillside area of RBGE}

The results gathered from the survey were then analysed with reference to the Chinese Hillside, an area of RBGE's Edinburgh Garden dedicated to Chinese species, particularly those that are IUCN red-listed and require conservation (Fig. 8). This analysis would enable themes identified in the survey to be tested, with potential problems highlighted and remedial action taken. The Chinese Hillside was officially opened to the public in 1997, and now contains approximately 1,600 plants (Rae et al., 2006). China is an active area of research in the Garden and demonstrates the partnership RBGE has had with Chinese botanic gardens for decades.

Will Hinchcliffe and Kirsty Wilson (Horticulture Supervisors) were tasked with removing dense planting that had begun to shade out the lower canopy vegetation. During a walk-round with the author, they identified problem areas and explained the decisions they had taken (Fig. 9). They expressed the importance of prioritising according to plant health, rarity and provenance.

Table 2 shows the importance of the data stored alongside individual accessions with regard to future decision-making. This is particularly important in the case of Pinus wallichiana, as it could easily have been deaccessioned due to it being common in cultivation.

Lack of space was the primary limiting factor within the Chinese Hillside. A lack of resources and time were considered secondary limiting factors due to the collection being outdoors (and therefore not requiring heating, additional lighting or irrigation), it being a low maintenance area and purposely kept wild to emulate how the plants look in nature. Maintaining high genetic diversity in ex situ conservation is vital for the gene pool (Gardner \& Thomas, 1996; Gardner et al., 2019). For example, a specimen of Cunninghamia konishii was removed because it was of limited genetic value. Conservation collections should aim to contain as much genetic diversity as possible within the accessions (Gardner \& Thomas, 1996; Christian, 2008; Gardner et al., 2019).

The investigation into the Chinese Hillside provided an opportunity to test the deaccessioning criteria for potential flaws. As seen in Table 2, these were largely avoided thanks to the amount of associated information logged when the plant material was first accessioned. This information is important as an aid to the decision-making process and to avoid deaccessioning valuable plant material. One example was a specimen of Pinus wallichiana which is unique due to its collection location and provenance. This specimen, if deaccessioned, would have resulted in a loss of valuable genetic material (Gardner \& Thomas, 1996; Christian, 2008; Gardner et al., 2019).

Another example illustrates the importance of associated information: a fine and mature specimen of Prumnopitys andina has been growing for years in the Nepalese area of the Garden, developed in 2017. The purpose of this part of the Garden is to display the many accessions of plants collected from Nepal and to reflect a key area of research for RBGE. This Chilean conifer does not fit the theme of the Nepalese garden but is a red-listed conifer (Threatened Conifers, 2019). The ICCP also has research and conservation programmes for the species, and so the plant is reflecting another part of the Garden's activities and therefore will not be removed.

This example confirms the results found in Fig. 7: that conservation is the primary 


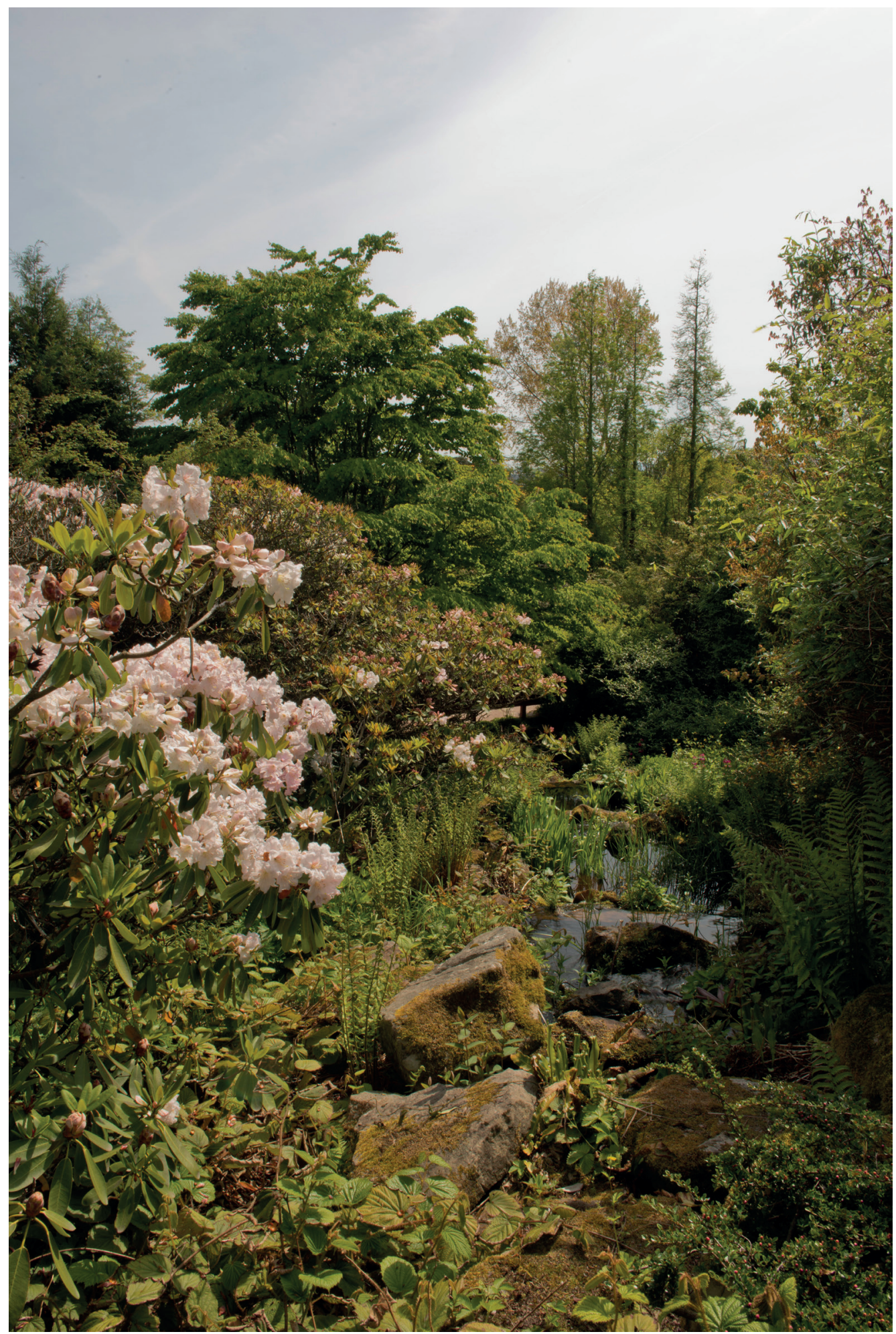

Fig. 8 The Chinese Hillside at RBGE. Photo: Lynsey Wilson. 


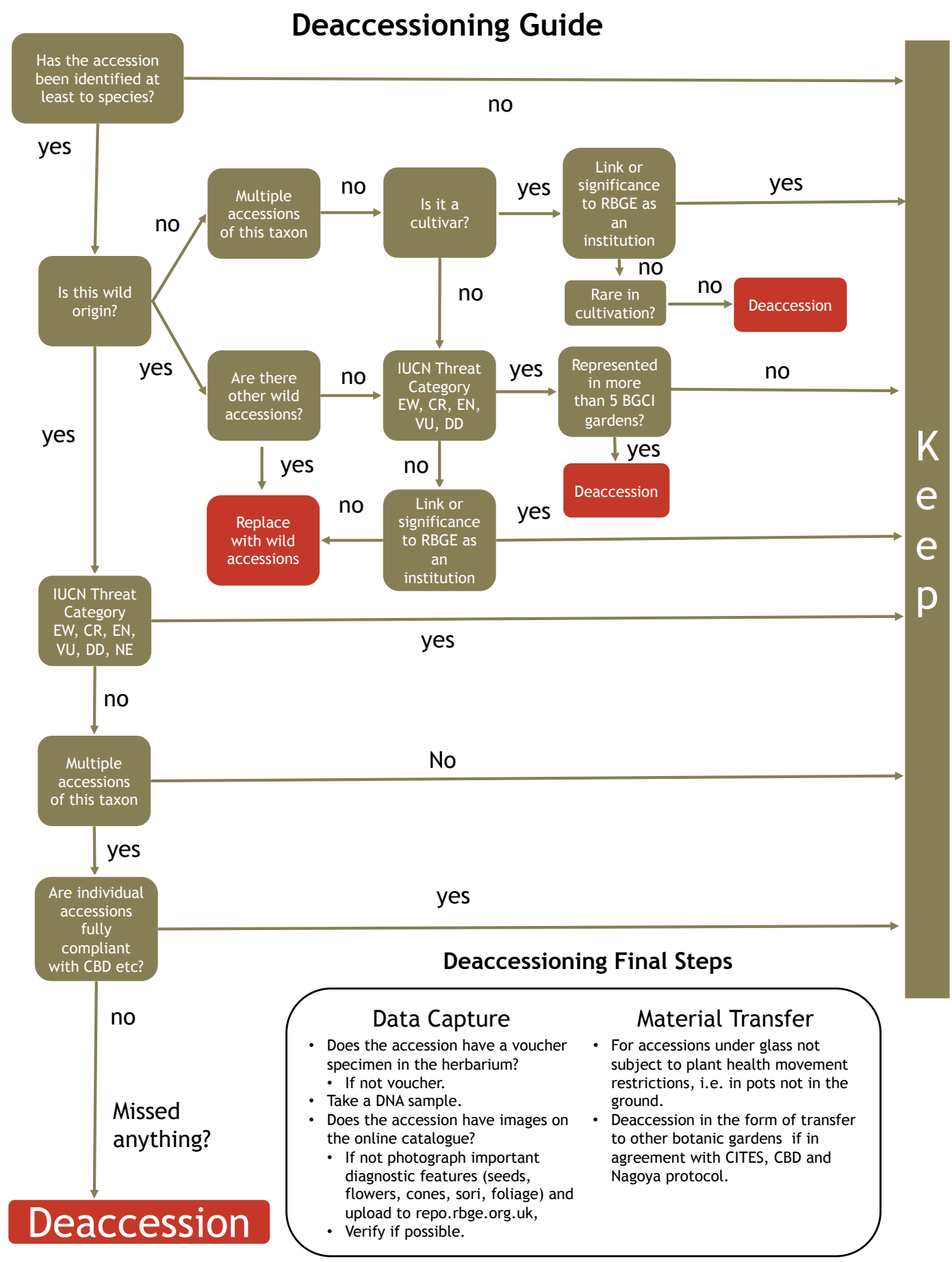

Fig. 9 An adapted version of the flow chart used at RBGE when deaccessioning. Information collected in the initial stages of the project indicates that herbarium voucher specimens were taken of deaccessioned material and that these specimens have been digitised. Deaccessioning guide: Alan Elliott for RBGE, 2019. 
Table 2 Decisions made in accordance with priority values for the Chinese Hillside and with associated data stored for each accession.

\begin{tabular}{|l|l|}
\hline \multicolumn{1}{|c|}{ Species } & \multicolumn{1}{c|}{ Action taken } \\
\hline Abies fabri & $\begin{array}{l}\text { Classed as Vulnerable (Threatened Conifers, 2019) so propagules will } \\
\text { be made of the plant to ensure that it is properly conserved. }\end{array}$ \\
\hline Acer macrophyllum & $\begin{array}{l}\text { Was listed for removal due to it not fitting the theme of the area. It is } \\
\text { not native to China and is not of conservation value. }\end{array}$ \\
\hline Betula platyphylla & $\begin{array}{l}\text { Was wild collected on a Sichuan expedition in 1988 and is the } \\
\text { healthiest tree so will be kept. }\end{array}$ \\
\hline Cunninghamia konishii & $\begin{array}{l}\text { One of multiple qualifiers (low genetic diversity) resulting in its } \\
\text { deaccessioning. }\end{array}$ \\
\hline Pinus wallichiana & $\begin{array}{l}\text { One of multiple specimens in the Garden but may be of significant } \\
\text { genetic importance as it was wild collected in China, as opposed to } \\
\text { Nepal, which is the country of origin of all the other specimens in the } \\
\text { collection. This specimen will be propagated. }\end{array}$ \\
\hline
\end{tabular}

consideration in the management of the collection. This supports the policy that rare species must be prioritised over cultivated collections of garden origin (NCBG, 2017; Rae et al., 2006; Glasgow Botanic Gardens, 2016).

\section{Discussion}

The results of the survey show that:

1. Not all the institutions surveyed have the same aims and objectives (Fig. 1);

2. The minimum data requirements for the accessioning of specimens are not met in all cases (Fig. 6).

The values shown in Fig. 1 do not have equal importance for all institutions.

However, most institutions regarded education as the most important; this is consistent with the findings of additional research carried out by the author on other institutions outwith the survey such as Glasgow Botanic Gardens (study conducted in 2016). All deemed research and display to be of significant importance. Many botanic gardens are trying to achieve a better partnership between aesthetics and science
(Johnson, 2013). The value of recreational green space was the factor with the lowest importance, as shown in Fig. 1. The findings of the present study contrast with those of Bennett \& Swasey (1996) and Connell (2004), who propose that recreation is one of the primary motivations for visitors to come to botanic gardens. A decrease in visitor numbers could impact on the future of the Garden. Conversely, the Garden has an obligation to attain its conservation and educational objectives if they have been identified as priority activities. A balance between all these values must therefore be found.

Expectations surrounding minimum data standards as stated in Thomas \& Watson (2000) vary depending on the intended use of the specimen within a collection (Rae et al., 2006). When comparing the information available on the plant labels throughout the 21 responding institutions, only the Latin binomial and the accession number remain constants (Fig. 3). Just two respondents (9.5 per cent) had all the suggested standard information on their plant labels. It has been suggested (Thomas \& Watson, 2000; Rae et al., 
2006) that the more data associated with an individual the more valuable and useful it is. While not all information on the plant labels is considered essential by the public, it is a useful aid for identification and maintaining accurate accession data (France, 2019). It is, however, crucial that all available information on the accession is stored permanently and securely, preferably electronically, so that it can be accessed by staff.

The average percentage of WCM in the institutions surveyed was 20 per cent (Fig. 4). These findings are consistent with Maunder et al. (2001), in that a large proportion of the collections surveyed contained plant material of non-wild origin and that 5 out of 18 gardens had collections of uncertain origin.

Two-thirds of the institutions surveyed had an accessioning policy (Fig. 2) and 61.9 per cent had a written deaccessioning policy (Fig. 5). Lack of clarity on deaccessioning adds to the uncertainty of the process, perpetuating the difficulties relating to correctly deaccessioning plant material. It is therefore suggested that an LCP should contain both an accessioning policy and a deaccessioning policy that are consistent with other institutional policies.

Surprisingly, the most controversial question (Fig. 6) was whether plants should be deaccessioned because of inadequate accession information. A lack of accession information is understandable when comparing older collections, as they often do not meet the minimum data requirements (Thomas \& Watson, 2000). Historic rare species collections and species potentially new to science sometimes have an incomplete data set associated with their accessions. Important material may be lost if deaccessioning is carried out solely according to the quality of the data for an accession. Critical analysis of the validity of the data is also necessary, as is using the most up-to-date information from multiple reliable sources (Suzanne Cubey \& Elspeth Haston, pers. comm.).

Botanic gardens should ideally be growing plants according to the purpose of the garden and the contribution the plants make towards meeting the collection developmental goals identified in the LCP. In theory, then, the purpose of a botanic garden and the factors considered before deaccessioning should be nearly identical. The results of the survey showed that conservation was of great importance with regard to the purpose of the garden and the deaccessioning process, but education was considered less important before deaccessioning (Fig. 7). If the purpose of a botanic garden is to educate, then plants of educational value should be of high importance and therefore not deaccessioned unless a suitable alternative is provided.

\section{Survey limitations}

The survey acknowledges a limited number of respondents (21) and is therefore not a representation of all horticultural institutions. However, to the author's knowledge, the present study is the first investigation into deaccessioning policies.

\section{Conclusion and recommendations}

Deaccessioning is an important curatorial process of managing a collection effectively. Justified, logical and responsible deaccessioning of plant material allows the overall standard of the collection to be improved. This has the potential to make the collection more meaningful and effective, and a greater resource of conservational, educational and interpretational value, as well as to make management more efficient. 
Based on the findings of the present study the following recommendations are made:

- Collection management is easier when the institution has an LCP containing an accessioning and deaccessioning policy. An LCP states the overarching aim of the garden, which may be considered an essential part of successful curation. Without this documentation, the institution will not be able to establish a clear direction. This can be rectified by adapting an LCP template in line with the conditions of the institution.

- Regular reassessment of the LCP involving the development of new collections and updated living collection development goals. Amendments to the accessioning policy may be required as the effects of climate change may have altered growing conditions.

- Improve records of accession data. This could happen at several points, both when plants are sourced and when they arrive at the garden.

- Prior to deaccessioning plant material, it is recommended that a herbarium specimen is taken and stored electronically, as well as a DNA sample.

This study hopes to highlight an overlooked aspect of curation. Deaccessioning is a common practice within botanic gardens but has not been studied in any great detail. Further research is required on the subject of deaccessioning and LCPs.

\section{Acknowledgements}

I would like to thank the RBGE horticultural staff and Research Associates David Knott, Alan Elliott, Sadie Barber, Will Hinchcliffe, Kirsty Wilson, David Rae and Stephen Blackmore for their assistance on the subjects of deaccessioning, botanic garden management and curation. Thanks also go to Martin Gardner for his relentless work on the ICCP and guidance while overseeing the project. Thank you to all who participated in the survey and to those who aided in its distribution. Finally, I am grateful to my supervisor Laura Cohen, as well as all the tutors who enabled me to complete the course and ultimately this project.

\section{References}

ALLNUTT, T., NEWTON, A., LARA, A., PREMOLI, A., ARMESTO, J., VERGARA, R. \& GARDNER, M. (1999). Genetic variation in Fitzroya cupressoides (alerce), a threatened South American conifer. Molecular Ecology, 8: 975-987.

\section{AMERICAN PUBLIC GARDENS ASSOCIATION}

(2019). About us. Available online: https://www. publicgardens.org/about-us (accessed November 2019).

BADLEY, C., HILL, D. \& WRAY, N. (2004). Inadequate accession data compromises the conservation value of plant collections. Sibbaldia: The Journal of Botanic Garden Horticulture, 2: 5-21.

BENEDICT, K. (1984). Invitation to a bonfire: reappraisal and deaccessioning of records as collection management tools in an archives - a reply to Leonard Rapport. American Archivist, 47(1): 43-49.

BENNETT, E.S. \& SWASEY, J.E. (1996). Perceived stress reduction in urban public gardens. HortTechnology, 6(2): 125-128.

BLACKMORE, S. (2008). Sibbaldia Guest Essay: Keep or compost? Why there must be life after research for living collections. Sibbaldia: The Journal of Botanic Garden Horticulture, 6: 5-8.

BOTANIC GARDENS CONSERVATION INTERNATIONAL (2012). Communities in nature: growing the social role of botanic gardens. Available online: http://www.bgci.org/education/ communities_in_nature (accessed November 2019).

BOTANIC GARDENS CONSERVATION INTERNATIONAL (2019). BGCI membership. 
Available online: https://www.bgci.org/ membership/our-members (accessed December 2019).

CHRISTIAN, T. (2008). A pilot study for the yew conservation hedge project at the Royal Botanic Garden Edinburgh. Unpublished BSc thesis, Scottish Agricultural College in conjunction with RBGE and the University of Glasgow.

COLLERAN, K. (2013). RBGE's carpological collection: a curatorial review. Unpublished BSc thesis, RBGE, SRUC and the University of Glasgow.

CONNELL, J. (2004). The purest of human pleasures: the characteristics and motivations of garden visitors in Great Britain. Tourism Management, 25(2): 229-247.

DOSSMAN, M.S. (2016). Curatorial Notes: An Updated Living Collections Policy at the Arnold Arboretum. Arnoldia, New York.

FLICK, U. (2009). An Introduction to Qualitative Research (4th edn). SAGE, London.

FRANCE, H. (2019). Student Project: A survey of bryophytes and their management in the ferns and fossils house at the Royal Botanic Garden Edinburgh. Sibbaldia: The Journal of Botanic Garden Horticulture, 17: 29-49.

FREDIANI, K. (2009). De Hortus Botanicus Amsterdam. Sibbaldia: The Journal of Botanic Garden Horticulture, 7: 121-138.

GARDNER, M., CHRISTIAN, T., HINCHCLIFFE, W. \& CUBEY, R. (2019). Conservation hedges: modern-day arks. Sibbaldia: The Journal of Botanic Garden Horticulture, 17: 71-100.

GARDNER, M. \& THOMAS, P. (1996). The International Conifer Conservation Programme (ICCP). New Plantsman, 7: 174-177.

GLASGOW BOTANIC GARDENS (2016). Curatorial policy for Glasgow Botanic Gardens (internal policy document). Glasgow Botanic Gardens, Glasgow.

GREENE, M. (2006). I've deaccessioned and lived to tell about it: Confessions of an unrepentant reappraiser. Archival Issues, 30(1): 7-22.

HOOKER, J. (1844). Icones plantarum 7: Biodiversity Library. Available online: https://www. biodiversitylibrary.org/page/16153783\#page/139/ mode/1up (accessed October 2019).

INTERNATIONAL DENDROLOGICAL SOCIETY (N.D.). Berberis $x$ stenophylla. Trees and Shrubs Online. Available online: https:// treesandshrubsonline.org/articles/berberis/ berberis-x-stenophylla (accessed October 2019).

JOHNSON, N. (2013). Cultivating science and planting beauty: the spaces of display in Cambridge's botanical gardens. Interdisciplinary Science Review, 31(1): 42-57.

KELLE, U. (2008). Combining qualitative and quantitative methods in research practice: purposes and advantages. Qualitative Research in Psychology, 3(4): 293-311.

KIM, Y.D., KIM, S. \& LANDRUM, L. (2004). Taxonomic and phytogeographic implications from ITS phylogeny in Berberis (Berberidaceae). Journal of Plant Research, 117(3): 175-182.

MAUNDER, M., HIGGENS, S. \& CULHAM, A. (2001). The effectiveness of botanic garden collection in supporting plant conservation: a European case study. Biodiversity and Conservation, 10: 383-401.

NORTH CAROLINA BOTANIC GARDEN (2017). Living collection policy (internal policy document). OXFORD DICTIONARY (2015). Oxford Dictionary of English (3rd edn). Oxford University Press, Oxford.

RAE, D. (1994). Royal Botanic Garden Edinburgh acquisition policy (internal policy document).

RAE, D. (1995). Botanic gardens and their live plant collections: present and future roles. Unpublished PhD thesis, University of Edinburgh.

RAE, D. (2004). Fit for purpose? The value of checking collection statistics. Sibbaldia: The Journal of Botanic Garden Horticulture, 2: 61-74.

RAE, D., BAXTER, P., KNOTT, D., MITCHELL, D., PATERSON, D. \& UNWIN, B. (2006). Collection Policy for the Living Collection (internal policy document).

RAE, D., CUBEY, R., HUGHES, K., GARDNER, M., THOMPSON, H., INCHES, F. \& KNOTT, D. (2012). Catalogue of Plants 2012. RBGE, Edinburgh.

RANDALL, D.M. \& FERNANDES, M.F. (1991). The social desirability response bias in ethics research. Journal of Business Ethics, 10: 805-817.

RICHARDS, L. (2005). Handling Qualitative Data: A Practical Guide. SAGE, London.

ROYAL BOTANIC GARDEN EDINBURGH (1994). Issue Plan for the Conservation of Plant Biodiversity. RBGE, Edinburgh. 
ROYAL BOTANIC GARDEN EDINBURGH (2000-

2012). Annual Reports. RBGE, Edinburgh.

SOCIETY OF AMERICAN ARCHIVISTS (2017).

Guidelines for Reappraisal and Deaccessioning.

Society of American Archivists, Chicago.

SONDERMAN, R. (1996). Primal fear:

deaccessioning collections. Common Ground, 1(2):

26-29.

STAM, D. (1982). Prove all things: hold fast that which is good. Deaccessioning and Research Libraries, 43(1): 5-13.
THOMAS, P. \& WATSON, M. (2000). Data Management for Plant Collections: A Handbook of Best Practice. RBGE, Edinburgh.

THREATENED CONIFERS (2019). RBGE. Available online: https://threatenedconifers.rbge.org.uk/ conifers/abies-fabri (accessed November 2019).

VECCO, M. \& PIAZZAI, M. (2015). Deaccessioning of museum collections: What do we know and where do we stand in Europe? Journal of Cultural Heritage, 16(2): 221-227. 